\title{
Effect of imipramine on the rheumatoid factor titre of psychotic patients with depressive symptomatology
}

\author{
G. G. HAYDU, L. GOLDSCHMIDT, AND A. D. DRYMIOTIS \\ From The Creedmoor Institute for Psychobiologic Studies, Queens Village, N. Y. 11427, U.S.A.
}

It was reported by Oreskes, Rosenblatt, Spiera, and Meadow (1968) that patients with depressive symptomatology show a high percentage of elevated rheumatoid factor titre as measured by the sensitized sheep cell test of Heller, Kolodny, Lepow, Jacobson, Rivera, and Marks (1955). They studied the blood samples of patients who were admitted to an acute psychiatric service. We were interested to ascertain whether the antidepressant medication imipramine has any effect on the titre of rheumatoid factor in depressed patients in need of antidepressant therapy. Haydu (1963) suggested that rheumatoid arthritis and depression are sequelae (in mutually exclusive directions) of a predepressive energy constellation that includes a high demand for adenosine triphosphate (ATP). In rheumatoid arthritis, the process was thought to be initiated by a high ATP-ase activity and a relative insufficiency of adrenocortical support. This hypothesis, based on metabolic studies (Haydu and Wolfson, 1950a, b), was responsible for the broaching of chloroquine therapy in 1951 (Haydu, 1951, 1953). Since then there is more direct evidence (BarwickSchramm and Kolodzieczyk, 1965) that, in rheumatoid arthritis, blood ATP concentrations are low and the levels correlate with the values of seromucoids and alpha-2 and gamma globulins as well as blood sugar curves. There is also more direct evidence that chloroquine inhibits obligatory aerobic ATP production of mitochondria (Ardneser and Heim, 1967; Stell and Thomas, 1972), and that it inhibits ATP-ase activity of the retina (Schmidt and Müller-Limmroth (1962)). According to the above, the study of imipramine effects on rheumatoid factor appeared feasible, especially since it was found (Tarve and Brechtlová, 1967) that imipramine reduced the activity of brain membrane-bound ATP-ase.

Beyond a double-blind design and a sufficiently long medication period under constant observation, we wished to establish two placebo-controlled observation periods, one preceding and one following the medication period. We also wished to observe patients in need of antidepressant therapy who have been stabilized in a controlled hospital setting (research ward) under an identical environmental and dietary regimen. Rosenblatt, Oreskes, Meadow, and Spiera (1968) found that schizophrenic patients differ significantly as regards rheumatoid factor titres according to whether they had depressive symptomatology or not. These cases of long duration who developed depressive symptomatology then appeared particularly appropriate for our study.

\section{Subjects and methods}

Patients were selected according to the following criteria:

(1) They were to be not older than 60 years, and suffering from a chronic schizophrenic process without signs of organicity.

(2) They had to be showing at the time of selection depressive symptomatology which in the opinion of the attending psychiatrist required imipramine therapy.

(3) They had to have no antidepressant therapy at the time of selection and transfer to the research ward.

(4) They had to be free of other illness and of rheumatological history.

They were given a placebo-controlled observation period of 6 weeks' duration followed by 6 weeks of imipramine therapy. The dosage of imipramine therapy was $50 \mathrm{mg}$. three times a day. The imipramine period was followed by a second placebo-controlled observation period which also lasted 6 weeks. Environmental and dietary conditions remained the same throughout.

During the three periods, bi-weekly observations were made of the following determinations:

\section{Psychiatric interviews.}

Depression scale rating (Zung).

Approach-avoidance preference test.

Psychomotor speed test.

Interaction indices at meals, with visitors, with patients, with nurses.

Nowlis Affect Check List.

Complete blood count.

Serum glutamic pyruvate transaminase.

Tanned sheep cell agglutination test.

Excepting the last test, all proved non-contributory or showed a non-significant trend. Therefore only the agglutination test will be described here. This followed the method of Heller and others (1955) as modified by Oreskes and others (1968). 


\section{Preparation of test sera}

Sheep heterophil antibodies were absorbed from test sera by adding to each specimen an equal amount of washed sheep blood cells. The mixture was refrigerated overnight and separated by centrifugation. The observed sera were inactivated at $56^{\circ} \mathrm{C}$. for $30 \mathrm{~min}$.

\section{Preparation of sheep red cells}

Sheep blood was obtained from Baltimore Biological Laboratories in Alsever solution 1:1. The cells were washed with glycine buffer pH 8.2. A 33.3 per cent. suspension of cells in buffer was mixed with an equal volume of a $1: 20,000$ dilution of tannic acid in buffer, and then incubated in a waterbath at $37^{\circ} \mathrm{C}$. for $10 \mathrm{~min}$. The mixture was then centrifuged, and the tanned cells were washed and then coated through incubation for $30 \mathrm{~min}$. with a 0.6 per cent. suspension of Cohn fraction II in buffer. After centrifugation and washing of the coated cells, a 0.25 per cent. suspension in buffer was made.

\section{Test procedure}

Serum specimens were diluted in buffer, in sequence from $1: 10$ to $1: 1,280$. To each one of these dilutions an equal, amount of sheep cell suspension was added $(0.5 \mathrm{ml}$.) and the mixture was kept overnight in the refrigerator. The next day tubes were examined for agglutination. Controls containing tanned but non-coated sheep cells were run simultaneously, and were negative throughout. Oreskes considered agglutination above dilution 1:40 to be positive. In our study the observation periods of the group constituted its controls.

\section{Results}

After screening, eliminations, and drop-outs, twelve patients were followed through the three periods as described above. Their ages ranged from 26 to 56 years. As indicated above, all observations except the sheep cell agglutination test was non-contributory or showed only non-significant trends. The initial agglutination titres in all cases were well above the normal. All patients showed agglutination at a dilution of $1: 640$, and nine out of twelve at a dilution of $1: 1,280$, confirming the previous reports on the positivity of this test in depressive symptomatology. The Table records the number of patients found positive at various dilutions in the three experimental periods. During the imipramine medication period, the titre became reduced substantially. In the following observation period, the titre still stayed substantially low but began to rise. Taking three bi-weekly figures together, the difference between the premedication control period and the medication period is significant at the 0.001 level. The difference between the postmedication period and the base observation period is also significant at the 0.001 level. The change in titre between the medication period and the subsequent observation period was not significant.

The psychiatric interviews were carried out by the psychiatrist who did not know the results of the titres described above. Six patients improved, two became worse, and four showed no change. It may be of interest to note that the patients who showed the most substantial reduction in titre were all in the improved group. There were three patients who showed a very high titre throughout the study. Two of them became worse and the third remained unchanged. This confirms the recent observations of Amkraut, Solomon, Allansmith, McClellan, and Rappaport (1973).

\section{Discussion}

These results support the view that the antidepressant drug imipramine, while affecting the energy dynamics of depression, reduces the high rheumatoid factor titre

Table Number of patients with positive agglutination at various dilutions in three experimental periods (determinations made bi-weekly)

\begin{tabular}{|c|c|c|c|c|c|c|}
\hline \multirow[t]{2}{*}{ Experimental periods } & \multicolumn{6}{|c|}{ Dilutions of sensitized sheep cells } \\
\hline & $1 / 40$ & $1 / 80$ & $1 / 160$ & $1 / 320$ & $1 / 640$ & $1 / 1,280$ \\
\hline Premedication (6 wks) & $\begin{array}{l}12 \\
12 \\
12\end{array}$ & $\begin{array}{l}12 \\
12 \\
12\end{array}$ & \begin{tabular}{|r}
12 \\
12 \\
12 \\
$\mathrm{~A}$ \\
\end{tabular} & $\begin{array}{l}11 \\
11 \\
12\end{array}$ & $\begin{array}{l}11 \\
10 \\
11\end{array}$ & $\begin{array}{l}9 \\
6 \\
9\end{array}$ \\
\hline Medication (6 wks) & $\begin{array}{l}12 \\
10 \\
10\end{array}$ & $\begin{array}{r}12 \\
7 \\
5\end{array}$ & \begin{tabular}{|r|}
11 \\
2 \\
5 \\
$\mathrm{~B}^{*}$ \\
\end{tabular} & $\begin{array}{l}9 \\
2 \\
3\end{array}$ & $\begin{array}{l}7 \\
0 \\
1\end{array}$ & $\begin{array}{l}4 \\
0 \\
1\end{array}$ \\
\hline Postmedication (6 wks) & $\begin{array}{l}10 \\
12 \\
12\end{array}$ & $\begin{array}{l}10 \\
10 \\
11\end{array}$ & $\begin{array}{c}7 \\
9 \\
10 \\
C^{*}\end{array}$ & $\begin{array}{l}3 \\
4 \\
8\end{array}$ & $\begin{array}{l}2 \\
3 \\
4\end{array}$ & $\begin{array}{l}1 \\
0 \\
2\end{array}$ \\
\hline
\end{tabular}

- Differs from A at the level of 0.001. 
found in depressed patients. It was somewhat surprising that the change was so prompt. After only 2 weeks the change began to show in most titres. Whether imipramine would reduce the titre of rheumatoid factor in rheumatoid arthritis without depression is an intriguing question. In a preliminary trial, however, we have found that it does.

The reported reduction of cerebral ATP-ase activity by imipramine should not be regarded as a uniform effect. Regional differences may very well be more appropriately related to antidepressant activity than the overall effect. The conformatory status of ATP-ase is intimately connected with sulphhydryl bonds and sulphhydryl disulphide interchange. Colloidal gold and penicillamine are among thiol exchange inhibitors, and they have been found useful in the treatment of rheumatoid arthritis. Chloroquine itself is an inhibitor of thiol groups. Not all sulphhydryl inhibitors, however, produce antirheumatic effects. Some mercurial inhibitors actually increase ATP-ase activity (Weber, 1959; Dreizen and Gershman, 1970) by a different conformational change. This may explain our observation (Haydu, 1956) that Mersalyl uniformly aggravates rheumatoid arthritis. This may also be the reason why inflammatory disease models were affected in a contradictory manner by various thiol group modifiers (Steinetz, Giannina, and Butler, 1973).

\section{Summary}

A double-blind, pre- and postmedication placebocontrolled study was made with imipramine in chronic psychotic patients with depressive symptomatology. Both environmental and dietary conditions remained the same throughout. The medication period lasted 6 weeks with $50 \mathrm{mg}$. imipramine three times a day. The preceding and following observation periods were of the same length. The initial uniformly high rheumatoid factor titres were significantly reduced by imipramine. This reduction continued to a lesser degree into the postmedication period. The results suggest that rheumatoid factor titre and the energy dynamics of depression are related.

\section{References}

Amkraut, A., Solomon, G. F., Allansmith, M., McClellan, B., and Rappaport, M. (1973) Arch. gen. Psychiat., 28, 673 (Immunoglobulins and improvement in acute schizophrenic reactions)

ARDUESER, G. A., AND HeIM, H. C. (1967) J. pharm. Sci., 56, 254 (Some effects of chloroquine on oxidative processes in rat heart)

Barwik-Schramm, A., AND KolodziejczyK, A. (1965) Reumatologia (Warsaw), 3, 111 (The values of adenosinetriphosphate (ATP) in the blood of rheumatic patients)

Dreizen, P., AND Gershman, L. C. (1970) Trans. N.Y. Acad. Sci., 32, 170 (Molecular basis of muscular contraction. Myosin)

HAYDU, G. G. (1951) 'Steroid function and rheumatoid arthritis', in 'Proc. II Europ. Congr. Rheumatology'. Scientia, Barcelona

- (1953) Amer. J. med. Sci., 225, 71 (Rheumatoid arthritis therapy: a rationale and the use of chloroquine diphosphate)

_ (1956) 'The psychobiologic disorder in rheumatoid arthritis', in 'III Int. Conf. Rheum. Dis., Aix-les-Bains'. (1963) Adv. psychosom. Med., 3, 196 (Integrative psychotherapy in rheumatoid arthritis and allied states)

-, AND Wolfson, A. H. (1950a) Rheumatism, 6, 9 (Studies on the pathogenesis of rheumatoid arthritis-I)

- _ - (1950b) Ibid., 6, 57 (Studies on the pathogenesis of rheumatoid arthritis-II)

Heller, G., Kolodny, M. H., Lepow, I. H., Jacobson, A. S., Rivera, M. E., and Marks, G. H. (1955) J. Immunol., 74, 340 (The hemagglutination test for rheumatoid arthritis. IV. Characterization of the rheumatoid agglutinating factors by analysis of serum fractions prepared by ethanol fractionation)

Oreskes, I., Rosenblatt, S., Spiera, H., ANd Meadow, H. (1968) Ann. rheum. Dis., 27, 60 (Rheumatoid factors in an acute psychiatric population)

Rosenblatt, S., Oreskes, I., Meadow, H., and Spiera, H. (1968) Amer. J. Psychiat., 124, 1640 (The relationship between antigammaglobulin activity and depression)

SChmidt, B., AND Müller-Limmroth, W. (1962) Acta ophthal. (Kbh.), Suppl. 70, p. 245 (Electroretinographic examinations following the application of chloroquine) 'First symposium of ISCERG, Stockholm, 1961', ed. G. Karpe)

Stell, J. G. P., AND Thomas, S. E. (1972) J. Pharm. Pharmacol., 24, 163 (The effect of chloroquine and its congeners on mitochondrial oxidation)

SteinetZ, B., Giannina, T., AND Butler, M. (1973) J. Pharmacol. exp. Ther., 185, 139 (The role of sulfhydryl groups in three models of inflammatory disease)

TARVE, U., AND BRECHTLOVA, M. (1967) J. Neurochem., 14, 283 (Effects of psychopharmacological agents on brain metabolism. III. Effects of imipramine and ouabain on the $(\mathrm{Na}++\mathrm{K}+)$-activated ATPase from brain microsomes and co-operative interactions with the enzyme)

Weber, H. H. (1959) Ann. N.Y. Acad. Sci., 81, 409 (The relaxation of the contracted actomyosin system) 